\title{
Retrieving and processing agro-meteorological data from API-client sources using R software
}

\author{
Adrian A. Correndo * (D), Luiz H. Moro Rosso ${ }^{*}$ (i) and Ignacio A. Ciampitti ${ }^{*}$ (i)
}

\begin{abstract}
Objectives: The main purpose of this publication is to help users (students, researchers, farmers, advisors, etc.) of weather data with agronomic purposes (e.g. crop yield forecast) to retrieve and process gridded weather data from different Application Programming Interfaces (API client) sources using R software.

Data description: This publication consists of a code-tutorial developed in $\mathrm{R}$ that is part of the data-curation process from numerous research projects carried out by the Ciampitti's Lab, Department of Agronomy, Kansas State University. We make use of three weather databases for which specific libraries were developed in R language: (i) DAYMET (Thornton et al. in https://daymet.ornl.gov/, 2019; https://github.com/bluegreen-labs/daymetr), (ii) NASA-POWER (Sparks in J Open Source Softw 3:1035, 2018; https://github.com/ropensci/nasapower), and (iii) Climate Hazards Group InfraRed Precipitation with Station Data (CHIRPS) (Funk et al. in Sci Data 2:150066, 2015; https://github.com/ ropensci/chirps). The databases offer different weather variables, and vary in terms of spatio-temporal coverage and resolution. The tutorial shows and explain how to retrieve weather data from multiple locations at once using latitude and longitude coordinates. Additionally, it offers the possibility to create relevant variables and summaries that are of agronomic interest such as Shannon Diversity Index (SDI) of precipitation, abundant and well distributed rainfall (AWDR), growing degree days (GDD), crop heat units (CHU), extreme precipitation (EPE) and temperature events (ETE), reference evapotranspiration (ETO), among others.
\end{abstract}

Keywords: Programming, Agriculture, Daymet, Nasapower, Chirps

\section{Objective}

The objective of this dataset [1] containing a code-tutorial is to assist end users to retrieve and process gridded weather data using $R$ software. This information can facilitate the collection of a diverse number of weather data parameters from multiple locations, in addition to assist on the rapid intake of data for multiple farming modeling systems to improve geo-spatial simulations considering weather as a key factor and to help us for scaling the results from multiple research projects. Two

*Correspondence: correndo@ksu.edu; Ihmrosso@ksu.edu; ciampitti@ksu.edu Department of Agronomy, Kansas State University, Manhattan, KS 66506, USA pertaining examples of the application of the code can be found in:

Correndo et al. [2]. Assessing the uncertainty of maize yield with no nitrogen fertilization. In Correndo et al. [2], gridded weather data from Daymet was obtained for 679 site-years across North America. Variables were summarized into monthly periods during the cropping season on maize, with the purpose of predicting the crop yield using a machine learning algorithm (conditional random forests).

Borja Reis et al. [3]. Environmental factors associated with nitrogen fixation prediction in soybean. In Borja Reis et al. [3], the code was used to obtain and process weather data for 95 site-years across the United States. 
Variables were summarized into custom periods (based on phenological stages) during the soybean cropping season, with the purpose of predicting soybean biological nitrogen fixation using a machine learning model (Elastic net).

\section{Data description}

All data files are deposited in the Harvard Dataverse repository, dataset "Agrometeorological data using R-software" [1]. The programming code (Data file 1 in Table 1) serves to retrieve weather data from multiple API-client sources and to produce secondary variables that are meaningful in agronomic terms. The R-code (".rmd) was generated using $\mathrm{R}$ version 4.0.3 (LinuxGNU, 64-bit) and R-studio v1.2.5042. However, additional machine specifications are not required in order to execute the $\mathrm{R}$ code. The time will be dependent on the volume of data (number of locations) and internet connection.

The API-client sources [4-9] offer different variables by default. Particularly, DAYMET offers the best combination of agrometeorological variables at the highest spatial resolution $\left(\sim 1 \mathrm{~km}^{-2}\right)$. However, the geographical coverage of DAYMET only includes North America. At a global scale, NASA-POWER offers the most complete set of variables, nonetheless, at a much lower spatial resolution $\left(\sim 50 \mathrm{~km}^{-2}\right)$. Lastly, CHIRPS offers global data $(-50$ to +50 latitude degrees) constrained to precipitations, however, with a better spatial resolution $\left(\sim 5 \mathrm{~km}^{-2}\right)$ than NASA-POWER.

In the tutorial file (Data file 2 in Table 1): (i) we provide extended explanations along with the lines of code showing how to download and process daily-weather data (Section 2 of the code), and (ii) we offer the option to generate new variables and summaries for different time intervals during the cropping season or historical periods (Sections 3 to 5 of the code). Details of calculations of secondary variables and summary options are provided in the Tutorial file.

The data table files (Dataset 1 and Dataset 2 in Table 1) represent examples of data inputs the user needs to provide in order to make the request of weather data to the data servers.

\section{Limitations}

- The code may be limited in the number of variables, which may not satisfy specific needs.

- Thermal time variables (growing degree days and Crop Heat Units) presented in the example are just for reference, using specifications for Zea mays $\mathrm{L}$. (corn, maize). For other crops, user should manually modify the specific lines of code.

- Although the Parameter elevation Regression on Independent Slopes Model (PRISM) database is available in R-software (https://docs.ropensci.org/ prism/), it does not allow users to directly retrieve multi-location weather data using latitude and longitude coordinates. For this reason, the PRISM library was not included on this tutorial. Next versions are likely to include the option of using PRISM.

\section{Abbreviations}

CHIRPS: Climate Hazards Group InfraRed Precipitation with Station Data; SDI: Shannon Diversity Index; AWDR: Abundant and well distributed rainfall; GDD: Growing degree days; $\mathrm{CHU}$ : Crop heat units; ETE: Extreme precipitation events (EPE); ETE: Extreme temperature events; ETO: Reference evapotranspiration.

\section{Acknowledgements}

Authors express their gratitude to the financial support provided by The Fulbright Program (Argentina), and Kansas Corn Commission, Corteva Agriscience, and Kansas State University for sponsoring AAC's Ph.D. progam and Dr. Ciampitti's research program. This manuscript is contribution no. 21-293-J from the Kansas Agricultural Experiment Station.

\section{Authors' contributions}

AAC contributed with the draft of the programming code, data-curation, visualization, and wrote the data-note draft. LHMR revised the programming code, visualization and revised the data-note. IAC revised the programming code, revised the data-note, and supervised the project. All authors read and approved the final manuscript.

\section{Funding}

Kansas State University and Kansas State Research and Extension.

\section{Availability of data and materials}

The data described in this Data note can be freely and openly accessed at Harvard Dataverse: https://doi.org/10.7910/DVN/J9EUZU [1]. Please see Table 1 and references [1] for details and links to the data.

Table 1 Overview of data files/data sets

\begin{tabular}{llll}
\hline Label & Name of data file/data set & File types (file extension) & Data repository and identifier (DOI or accession number) \\
\hline Data file 1 & Code_agromet_R & RMarkdown file (.rmd) & Harvard Dataverse: https://doi.org/10.7910/DVN/J9EUZU [1] \\
Data file 2 & Tutorial_agromet_R & PDF file (.pdf) & Harvard Dataverse: https://doi.org/10.7910/DVN/J9EUZU [1] \\
Dataset 1 & Example_input & CSV file (.csv) & Harvard Dataverse: https://doi.org/10.7910/DVN/J9EUZU [1] \\
Dataset 2 & Example_input_historical & CSV file (.csv) & Harvard Dataverse: https://doi.org/10.7910/DVN/J9EUZU [1] \\
\hline
\end{tabular}




\section{Declarations}

Ethics approval and consent to participate

Not applicable.

\section{Consent for publication}

Not applicable.

\section{Competing interests}

Authors declare no competing interests.

Received: 29 January 2021 Accepted: 18 May 2021

Published online: 26 May 2021

\section{References}

1. Correndo AA, Moro Rosso LH, Ciampitti IA. Agrometeorological data using R-software. Harvard Dataverse. 2021. https://doi.org/10.7910/DVN/ J9EUZU.

2. Correndo AA, Rotundo JL, Tremblay N, Archontoulis S, Coulter JA, RuizDiaz D, Franzen D, Franzluebbers A, Nafziger E, Schwalbert R, Steinke K, Williams J, Messina CD, Ciampitti IA. Assessing the uncertainty of maize yield with no nitrogen fertilization. Field Crops Res. 2021;260:107985. https://doi.org/10.1016/j.fcr.2020.107985.
3. BorjasReis AF, MoroRosso LH, Purcell LC, Naeve S, Casteel S, Kovacs P, Archontoulis S, Davidson D, Ciampitti IA. Environmental factors associated with nitrogen fixation prediction in soybean. Front Plant Sci. 2021. https://doi.org/10.3389/fpls.2021.675410.

4. Thornton PE, Thornton M, Mayer B, Wei Y, Devarakonda R, Vose R, Cook RB. Daymet: daily surface weather data on a 1-km grid for North America, Version3. ORNL DAAC, Oak Ridge, Tennessee, USA. 2019. https://daymet. ornl.gov/.

5. https://github.com/bluegreen-labs/daymetr.

6. Sparks A. nasapower: a NASA power global meteorology, surface solar energy and climatology data client for R. J Open Source Softw. 2018;3(30):1035. https://doi.org/10.21105/joss.01035.

7. https://github.com/ropensci/nasapower.

8. Funk C, Peterson P, Landsfeld M, Pedreros D, Verdin V, Shukla S, Michaelsen J. The climate hazards infrared precipitation with stationsa new environmental record for monitoring extremes. Sci Data. 2015;2:150066. https://doi.org/10.1038/sdata.2015.66.

9. https://github.com/ropensci/chirps.

\section{Publisher's Note}

Springer Nature remains neutral with regard to jurisdictional claims in published maps and institutional affiliations.
Ready to submit your research? Choose BMC and benefit from:

- fast, convenient online submission

- thorough peer review by experienced researchers in your field

- rapid publication on acceptance

- support for research data, including large and complex data types

- gold Open Access which fosters wider collaboration and increased citations

- maximum visibility for your research: over 100M website views per year

At BMC, research is always in progress.

Learn more biomedcentral.com/submissions 